Fetal Diagnosis

ant Therapy

\title{
Ductus Venosus in the First Trimester: Contribution to Screening of Chromosomal, Cardiac Defects and Monochorionic Twin Complications
}

\author{
Nerea Maiz ${ }^{a}$ Kypros H. Nicolaides ${ }^{b, c}$ \\ ${ }^{a}$ Fetal Medicine Unit, Centro Sanitario Virgen del Pilar, San Sebastián, Spain; ${ }^{b}$ Harris Birthright Research Centre for \\ Fetal Medicine, King's College Hospital, and ' Fetal Medicine Unit, University College Hospital, London, UK
}

\section{Key Words}

Ductus venosus $\cdot$ Chromosomal abnormality $\cdot$ Heart defect $\cdot$ First trimester • Twin-to-twin transfusion syndrome

\begin{abstract}
In the first trimester the ductus venosus can be easily identified with color Doppler and a ductus venosus waveform can be obtained by pulsed Doppler. At 11-13 weeks the prevalence of abnormal a-wave in the ductus venosus is inversely related to fetal crown-rump length and maternal serum pregnancy-associated plasma protein-A (PAPP-A), increases with fetal nuchal translucency (NT) thickness and is more common in women of Black racial origin and in fetuses with abnormal karyotype or cardiac defects. Ductus venosus flow provides an independent contribution in the prediction of chromosomal abnormalities when combined with NT and the maternal serum markers of PAPP-A and free $\beta-\mathrm{hCG}$, increasing the detection rate to $96 \%$ at a false-positive rate of $2.6 \%$. Abnormal ductus venosus flow increases the risk of cardiac defects in fetuses with NT above the 95th centile, and it may increase the risk in fetuses with normal NT. In twin pregnancies, abnormal ductus venosus flow is associated with chromosomal abnormalities and cardiac defects. In monochorionic twins, abnormal flow in the ductus venosus in at least 1 of the fetuses increases the risk of developing twin-to-twin transfusion syndrome.
\end{abstract}

Copyright $\odot 2010$ S. Karger AG, Basel

\section{KARGER \\ Fax +4161306 1234 \\ E-Mail karger@karger.ch}

www.karger.com (c) 2010 S. Karger AG, Basel

$1015-3837 / 10 / 0282-0065 \$ 26.00 / 0$

Accessible online at:

www.karger.com/fdt

\section{Introduction}

The 11- to 13-week scan is now widely accepted as an important component of early screening for fetal chromosomal and structural defects and for preeclampsia [13]. Assessment of the ductus venosus flow is an integral part of the 11- to 13-week scan because extensive studies have demonstrated that abnormal flow in this vessel is associated with an increased risk for chromosomal abnormalities, cardiac defects and other adverse pregnancy outcomes both in singletons and twin pregnancies [4-6].

Anatomically, the ductus venosus is strategically located as it has an important role directing the oxygenated blood towards the fetal heart and brain. About $30 \%$ of the oxygenated blood from the umbilical vein, which is distributed to the portal vein, is shunted through the ductus venosus $[7,8]$. The degree of shunting will be determined by the diameter of the vessel, pressure gradient and blood viscosity [9]. The blood from the ductus venosus is then directed towards the left atrium as a consequence of the anatomical position of the fetal atrial septum, which is located further to the right than in the postnatal life, and the high volume and velocity of the blood flow from the ductus venosus that distends the foramen ovale flap like a spinnaker [10]. Different conditions affecting the cardiac pre- or afterload may produce pressure gradient changes and affect the ductus venosus waveform. 
Fig. 1. Ductus venosus color Doppler (left) and ductus venosus waveforms (right) showing the three phases: (S) systole, (D) diastole, and (a) atrial contraction.
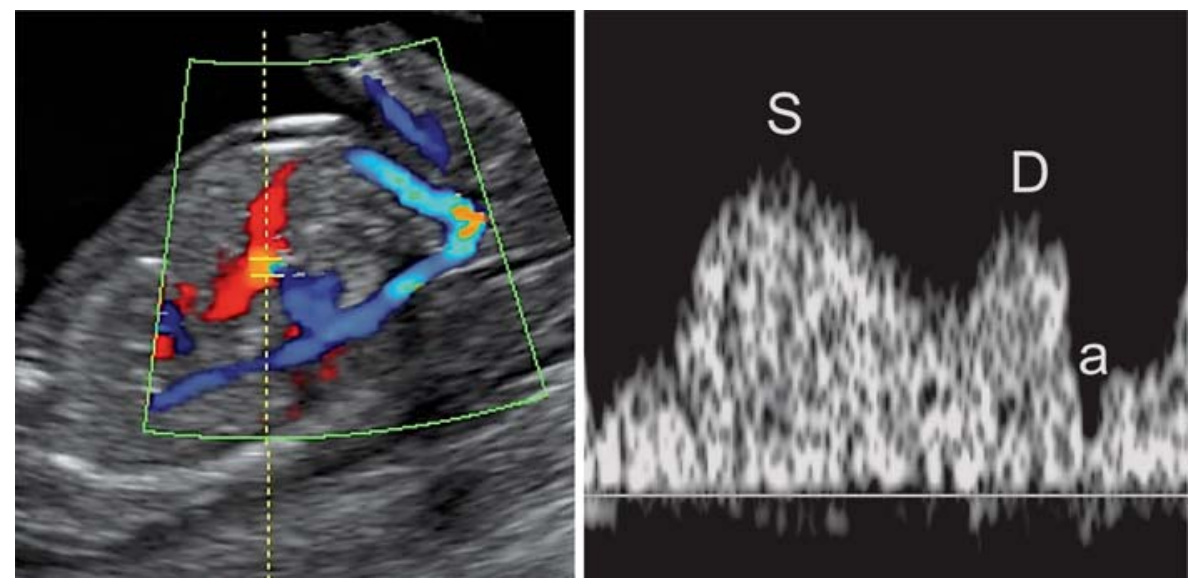

Fig. 2. Flow velocity waveforms showing a normal waveform (a), reversed a-wave (b), contamination by umbilical vein (c) showing a truncated $\mathrm{V}$-shaped line and contamination by hepatic vein (d) showing two Vshaped lines [13].
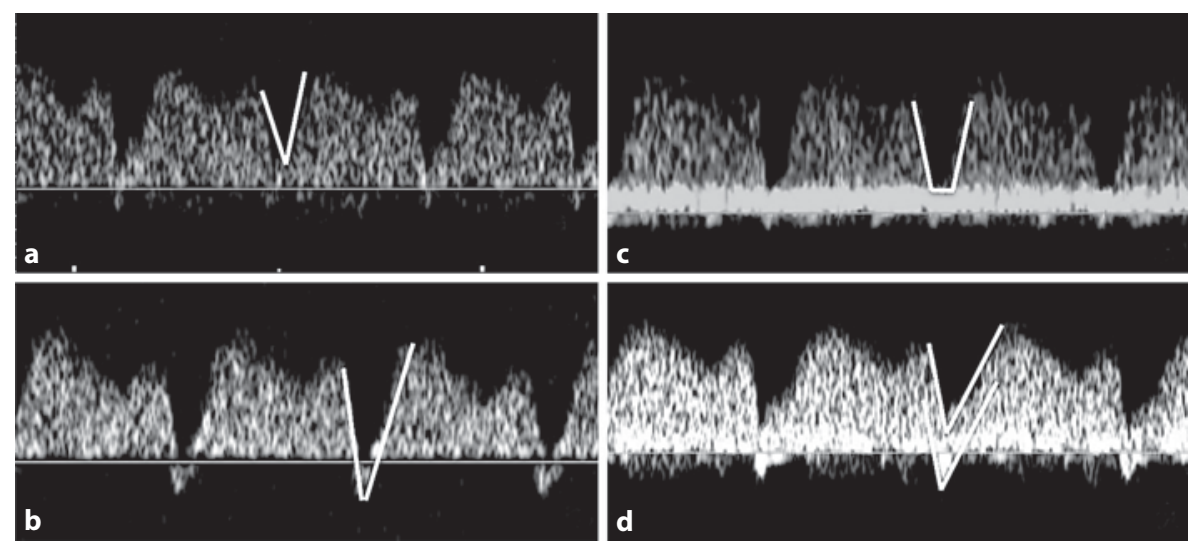

\section{Assessment of Ductus Venosus Flow}

In the first trimester, the ductus venosus can be easily identified by color Doppler mapping as the portion with higher velocity following the umbilical vein. The ductus venosus has a typical waveform where three phases can be recognized. The highest velocity peak corresponds to the ventricular systole (S); during this phase the pressure gradient between the umbilical vein and the atrium is the highest. The next peak of forward flow corresponds to the early diastole (D), with the opening of the atrioventricular valves and early passive filling of the ventricles. The third phase, with the lowest velocity, corresponds to the atrial contraction (a) during late diastole; during this phase the atrial pressure is high and there is a low pressure gradient [11] (fig. 1).

Doppler assessment of the ductus venosus should fulfill the following criteria: (1) the examination should be taken under fetal quiescence; (2) the magnification of the image should be such that the fetal thorax and abdomen occupy the whole screen; (3) a right ventral mid-sagittal view of the fetal trunk should be obtained and color flow mapping used to demonstrate the umbilical vein, ductus venosus and fetal heart; (4) the pulsed Doppler sample should be small $(0.5-1 \mathrm{~mm})$ to avoid contamination from the adjacent veins, and it should be placed in the yellowish aliasing area, which is the portion immediately above the umbilical sinus; (5) the insonation angle should be $<30^{\circ}$; (6) the filter should be set at a low frequency $(50-70 \mathrm{~Hz})$ so that the a-wave is not obscured, and (7) the sweep speed should be high $(2-3 \mathrm{~cm} / \mathrm{s})$ so that the waveforms are spread allowing better assessment of the a-wave $[12,13]$.

Waveforms can be assessed quantitatively, the most frequently used parameter is the pulsatility index for veins [14], or qualitatively, classifying the a-wave as positive, absent or reversed according to the forward, absent or reversed flow, respectively, during the atrial contraction [15] (fig. 2).

A correct technique should be used to assess the ductus venosus waveform in order to avoid contamination from the adjacent veins, the main artifact in ductus venosus assessment. Contamination by the inferior vena cava 
Table 1. Studies reporting on the incidence of abnormal flow in the ductus venosus in the first trimester in euploid fetuses and in those with trisomy $21,18,13$, Turner syndrome and other chromosomal abnormalities

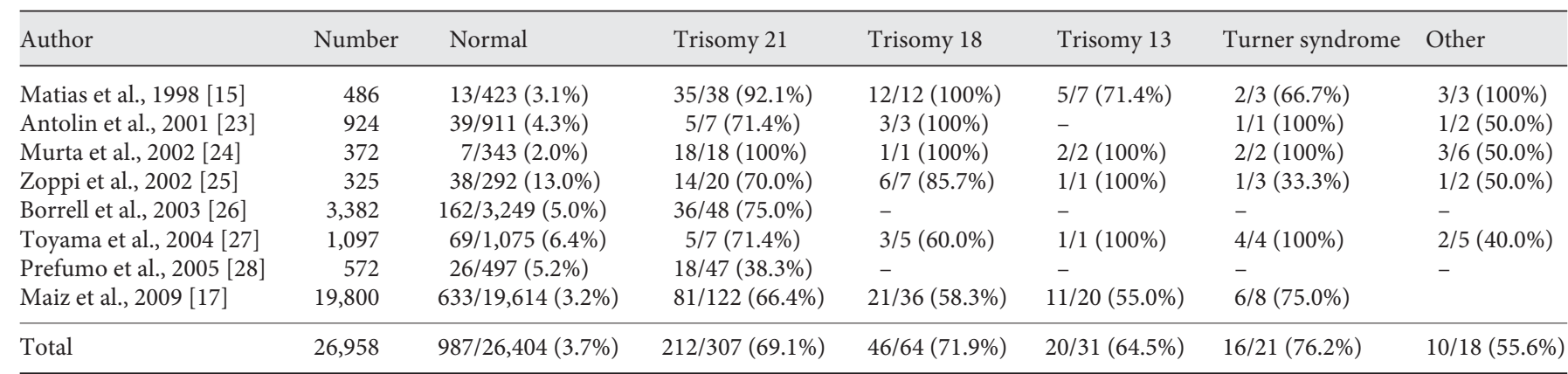

Abnormal flow was defined as absent or reverse $\alpha$-wave or pulsatility index for veins above the 95 th centile.

or hepatic veins may mimic a reversed a-wave and, conversely, contamination by the umbilical vein may hide an absent ductus venosus a-wave. According to Borrell [13], in the contamination by inferior vena cava or hepatic veins, two V-shaped lines are seen, while in true reversed flow the line delineated by maximum velocity follows a single continuous V-shaped line, crossing zero. In contamination by the umbilical vein, a 'truncated' $\mathrm{V}$ line is seen (fig. 2). Competence in accurate assessment of the ductus venosus waveform requires extensive supervised training. Maiz et al. [12] showed that an experienced sonographer needs about 80 supervised scans in order to achieve this level of competence.

\section{Ductus Venosus Flow in Normal Pregnancies}

At 11-13 weeks, blood flow during atrial contraction is usually forward, although absent or reversed flow might be recorded in normal fetuses [16]. The prevalence of reversed a-wave is inversely related to the fetal crownrump length and maternal serum pregnancy-associated plasma protein-A (PAPP-A) and is more common in women of Black racial origin [17]. There are three factors that may explain the crown-rump length-related decrease in the prevalence of reversed a-wave: (a) improved ventricular filling and decreased myocardial stiffness with advancing gestation, (b) decrease in placental resistance and therefore cardiac afterload, and (c) improvement in renal function to counteract any tendency to fluid retention [18-21]. The increased cardiac afterload due to impaired placentation and therefore increased placental resistance may explain the association between the reversed a-wave with low PAPP-A and Black racial origin [17].

\section{Ductus Venosus Flow and Screening for Chromosomal Abnormalities}

In fetuses with chromosomal abnormalities there is a higher prevalence of abnormal ductus venosus waveform [22]. In the combined data from eight studies, abnormal ductal blood flow was observed in $3.7 \%$ of euploid fetuses and in $69.1,71.3,64.5$ and $76.2 \%$ of fetuses with trisomies 21, 18 and 13 and Turner syndrome, respectively (table 1) $[15,17,23-28]$.

Different studies have assessed ductus venosus flow at 11-13 weeks together with other first-trimester markers. Several studies showed a significant correlation between ductus venosus flow and nuchal translucency (NT) thickness $[5,17,26,29]$. This might be explained by the coincidence of cardiac defects or transient cardiac dysfunction [21]. One study examined the association between ductus venosus flow and nasal bone and found no significant interaction [28]. Two studies have found a significant association between ductus venosus flow and maternal serum PAPP-A MoM [17, 30]. A possible explanation for this association would be that low levels of PAPP-A are reflecting an early impaired placentation leading to an increased placental resistance and high cardiac afterload.

Logistic regression analysis has shown that ductus venosus flow provides independent contribution to the prediction of chromosomal abnormalities when it is combined with NT and maternal serum PAPP-A and free $\beta$ hCG $[17,30,31]$.

Performance of first-trimester combined screening for trisomy 21 is improved by the addition of ductus venosus flow assessment at 11-13 weeks. Maiz et al. [17] found an increase in the detection rate from 94 to $97 \%$ and from 80 
Table 2. Previous studies that examined the relationship between ductus venosus waveforms and major cardiac defects in chromosomally normal fetuses with NT thickness above the 95th centile

\begin{tabular}{lrccc}
\hline Author & Total & $\begin{array}{l}\text { Cardiac } \\
\text { defects }\end{array}$ & \multicolumn{2}{c}{ Abnormal ductus venosus flow } \\
\cline { 4 - 5 } & & & no cardiac defects & cardiac defects \\
\hline Matias et al., 1999 [21] & 142 & $7(4.9 \%)$ & $4 / 135(3.0 \%)$ & $7 / 7(100 \%)$ \\
Bilardo et al., 2001 [29] & 69 & $4(5.8 \%)$ & $19 / 65(29.2 \%)$ & $4 / 4(100 \%$ \\
Murta et al., 2002 [24] & 16 & $1(6.3 \%)$ & $0 / 15(0.0 \%)$ & $1 / 1(100 \%)$ \\
Zoppi et al., 2002 [25] & 115 & $2(1.7 \%)$ & $30 / 113(26.5 \%)$ & $2 / 2(100 \%)$ \\
Haak et al., 2003 [33] & 22 & $2(9.1 \%)$ & $8 / 20(40.0 \%)$ & $2 / 2(100 \%)$ \\
Favre et al., 2003 [34] & 95 & $9(9.5 \%)$ & $20 / 86(23.3 \%)$ & $9 / 9(100 \%)$ \\
Toyama et al., 2004 [27] & 141 & $4(2.8 \%)$ & $23 / 137(16.8 \%)$ & $3 / 4(75 \%)$ \\
Maiz et al., 2008 [32] & 191 & $16(8.4 \%)$ & $40 / 175(22.9 \%)$ & $11 / 16(68.8 \%)$ \\
\hline Total & 791 & $45(5.7 \%)$ & $144 / 746(19.3 \%)$ & $39 / 45(86.7 \%)$ \\
\hline
\end{tabular}

to $88 \%$ for fixed false-positive rates of 5 and $1 \%$, respectively. Similarly, Borrell et al. [31] by addition of the ductus venosus to NT and serum markers found a detection rate of 92 and $88 \%$ for false-positive rates of 5 and $1 \%$, respectively.

Different screening strategies have been studied: (a) assessment of the ductus venosus at 11-13 weeks in all cases, (b) a two-stage strategy, with a first-stage screening using the combined test in all patients followed by a second-stage assessment of the a-wave only in those with an intermediate risk of 1 in 51 to 1 in 1,000 after the first stage, (c) an integrated test, with measurements of NT and PAPP-A in the first trimester and measurements of $\alpha$-fetoprotein, unconjugated estriol, free $\beta$-hCG and inhibin-A in the second trimester (15-20 weeks). Maiz et al. [17] studied the first two strategies and found similar results with detection rates of 96 and $95.9 \%$ at a false-positive rate of $2.6 \%$. Borrell et al. [30] investigated the integrated test and reported that the detection rates were 95 and $93 \%$ at false-positive rates of 5 and 3\%, respectively.

\section{Ductus Venosus Flow and Screening for Cardiac Defects}

Abnormal flow in the ductus venosus is associated with increased risk for fetal cardiac defects. Early studies examining this association focused on fetuses with increased NT, but more recent studies have reported data on fetuses with normal NT.

In chromosomally normal fetuses with increased fetal $\mathrm{NT}$, the finding of absent or reversed a-wave in the ductus venosus is associated with a threefold increase in the like- lihood of a major cardiac defect, whereas the finding of normal ductal flow is associated with a halving in the risk for such defects [32]. In the combined data from eight studies that examined ductus venosus waveforms in 791 chromosomally normal fetuses with increased NT thickness (above the 95th centile) a major cardiac defect was observed in 45 (5.7\%) fetuses and 39 (86.7\%) of these had abnormal Doppler waveforms in the ductus venosus (table 2) $[21,24,25,27,29,32-34]$. However, there were wide variations between the individual studies in the number of cases examined (16-191), the prevalence of cardiac defects (1.7-9.5\%), and the incidence of abnormal ductus venosus waveforms in those without cardiac defects (0$40 \%)$.

A more recent study assessed the performance of the ductus venosus in the prediction of cardiac defects in a screening population. This study involved 10,490 fetuses, including $20(0.2 \%)$ with major cardiac defects, and found a higher prevalence of reversed a-wave in those fetuses with cardiac defects than in those without cardiac defects (25 vs. $3.7 \%$ ). In a multiple logistic regression analysis, abnormal ductus venosus flow and NT measurement were the only contributors in the prediction of cardiac defects [5].

The results of the studies in euploid fetuses with normal NT are contradictory. In the study by Maiz et al. [5], none of the 12 fetuses with cardiac defect and normal NT had abnormal ductus venosus flow. Martinez et al. [35] found that 5 of $32(15.6 \%)$ fetuses with a major cardiac defect and normal NT had a reversed a-wave in the ductus venosus. In a case-control study in fetuses with normal NT, Oh et al. [4] found that fetuses with abnormal flow in the ductus venosus had a higher prevalence of 
cardiac defects than those with normal ductus venosus flow.

Martinez et al. [35] found no specific pattern of major cardiac defects in fetuses with increased NT and abnormal ductus venosus flow, but right heart abnormalities were predominant ( 4 out of $5,80 \%$ ) in fetuses with normal NT with abnormal flow in the ductus venosus. Some of the structural heart defects that are not associated with heart failure during the second and third trimesters but with heart failure after birth have a reversed a-wave in the ductus venosus in the first trimester $[21,36,37]$. The fetal heart has a lower compliance than an adult heart and this is more evident in the first trimester, where the predominance of the atrial contraction wave is greater than in later gestation. In addition, cardiac afterload is greater in the first trimester because of higher placental resistance. Thus, in the first trimester, only a small impairment of the cardiac diastolic function might be enough for cardiac dysfunction to become evident as a reversed a-wave in the ductus venosus $[15,21,22]$.

\section{Ductus Venosus Flow and Screening for Monochorionic Twins Complications}

Very few studies have analyzed ductus venosus flow at 11-13 weeks in twin pregnancies. The association of abnormal flow in the ductus venosus with fetal aneuploidies and cardiac defects is similar to that in singleton pregnancies. In a study with 695 twin pregnancies, 516 dichorionic and 179 monochorionic, there was a similarly high prevalence of reversed a-wave in aneuploid compared with euploid fetuses ( $70 \mathrm{vs.} 7.7 \%, \mathrm{p}<0.001$ ) as in singleton pregnancies, and assessment of the ductus venosus flow improved the prediction of aneuploidies provided by screening with fetal NT alone. In the same study, 3 of the $6(50.0 \%)$ fetuses with a major cardiac defect had an abnormal flow in the ductus venosus [6].

A small study by Matias et al. [38] suggested that abnormal ductus venosus flow in the first trimester may be a predictor of twin-to-twin transfusion syndrome (TTTS). In a series of 11 monochorionic twin pregnancies, severe TTTS developed in the 2 cases with abnormal ductus venosus waveforms in the recipient fetus at 11-13 weeks of gestation and in none of the cases with normal ductus venosus flow patterns. Subsequently, two larger studies have analyzed this association. Maiz et al. [6], in a series of 179 monochorionic pregnancies, found a reversed a-wave in 10 of the 26 pregnancies (38.5\%) that subsequently developed a TTTS. The rate of development of TTTS was $15 \%$, which was increased to $30 \%$ if there was a reversed a-wave in 1 of the fetuses and reduced to $10 \%$ if the ductus venosus flow was normal in both fetuses at 11-13 weeks. Matias et al. [39] have recently found abnormal flow in the ductus venosus in 9 of the 12 (75.0\%) of the pregnancies that subsequently developed TTTS and 9 of the $16(56.3 \%)$ pregnancies where 1 of the fetuses had an abnormal waveform developed TTTS. Despite the differences in the two studies, it seems clear that abnormal flow in the ductus venosus in at least 1 of the fetuses at 11-13 weeks increases the risk of developing TTTS and, therefore, the intensity of monitoring of such pregnancies should be increased.

The prevalence of reversed a-wave in fetuses from singleton pregnancies and dichorionic twins is similar, but in monochorionic twins it is substantially higher, even in those that do not develop TTTS [6]. It is possible that in pregnancies with abnormal Doppler and normal outcome there is spontaneous resolution of TTTS between the first and second trimesters and, in contrast, in those with normal Doppler and subsequent TTTS the hemodynamic abnormality develops during the second trimester. This is compatible with the hypothesis of 'asymmetric reduction in placental anastomoses' [40]. According to this hypothesis, in all monochorionic twins in early pregnancy, there is a large of number of bidirectional arteriovenous connections but with advancing gestation there is progressive spontaneous closure or disruption in these anastomoses, which occurs at random. Clinical features of TTTS occur when there is asymmetry in the arteriovenous anastomoses so that there is a net flow of blood in favor of one of the fetuses and at the expense of its cotwin. It is therefore possible that in some pregnancies with asymmetrical flow at 11-13 weeks, with advancing gestation, the random disruption of arteriovenous anastomoses restores symmetry in flow and therefore spontaneous resolution of the early sign of TTTS. In contrast, in some cases with symmetrical flow at 11-13 weeks the subsequent disruption of arteriovenous anastomoses is asymmetrical resulting in the development of TTTS during the second trimester. Previous studies reported that another early manifestation of TTTS is increased NT in at least 1 of the fetuses or a large discordance in NT between the 2 fetuses [41, 42]. Multiple regression analysis demonstrated that in the prediction of TTTS there was no significant improvement by the addition of NT discordance to the finding of reversed a-wave $[6,39]$. 


\section{Conclusions}

Ductus venosus flow assessment at the 11- to 13-week scan has an important role in screening for chromosomal abnormalities and cardiac defects both in singleton and in twin pregnancies.

Ductus venosus flow assessment improves the performance of screening for chromosomal abnormalities provided by combined screening by NT thickness and serum PAPP-A and free $\beta$-hCG, and is also a useful tool in firsttrimester screening for cardiac defects. Different strategies have been suggested. One option is to assess ductus venosus in all patients. Alternatively, since accurate as- sessment requires an extensive supervised training, it could be assessed by sonographers with this level of competence only in those patients that have an intermediate risk between 1 in 51 and 1 in 1,000 after the first-stage screening and in those fetuses with an increased NT thickness above the 95th centile. This way the number of patients requiring an assessment by a specifically trained sonographer would be reduced to no more than $20 \%$. The detection rate of chromosomal abnormalities by the two approaches is the same. In twin pregnancies ductus venosus flow has similar applications as in singleton pregnancies, and in monochorionic twins it helps to modify the intensity of monitoring in search for TTTS.

\section{References}

$>1$ Kagan KO, Wright D, Valencia C, Maiz N, $>11$ Kiserud T, Eik-Nes SH, Blaas HG, Hellevik Nicolaides KH: Screening for trisomies 21, 18 and 13 by maternal age, fetal nuchal translucency, fetal heart rate, free $\beta$-HCG and pregnancy-associated plasma protein-A. Hum Reprod 2008;23:1968-1975.

$\checkmark 2$ Becker R, Wegner RD: Detailed screening for fetal anomalies and cardiac defects at the 11-13-week scan. Ultrasound Obstet Gynecol 2006;27:613-618.

$\checkmark 3$ Poon LC, Kametas NA, Maiz N, Akolekar R, Nicolaides KH: First-trimester prediction of hypertensive disorders in pregnancy. Hypertension 2009;53:812-818.

$\checkmark 4$ Oh C, Harman C, Baschat AA: Abnormal first-trimester ductus venosus blood flow: a risk factor for adverse outcome in fetuses with normal nuchal translucency. Ultra sound Obstet Gynecol 2007;30:192-196.

$\checkmark 5$ Maiz N, Valencia C, Emmanuel EE, Staboulidou I, Nicolaides KH: Screening for adverse pregnancy outcome by ductus venosus Doppler at 11-13 + 6 weeks of gestation. Obstet Gynecol 2008;112:598-605.

6 Maiz N, Staboulidou I, Leal AM, Minekawa R, Nicolaides KH: Ductus venosus Doppler at 11 to 13 weeks of gestation in the prediction of outcome in twin pregnancies. Obstet Gynecol 2009;113:860-865.

$>7$ Kiserud T, Rasmussen S, Skulstad S: Blood flow and the degree of shunting through the ductus venosus in the human fetus. Am J Obstet Gynecol 2000;182:147-153.

$>8$ Kiserud T, Rasmussen S: Ultrasound assessment of the fetal foramen ovale. Ultrasound Obstet Gynecol 2001;17:119-124.

$>9$ Kiserud T, Acharya G: The fetal circulation. Prenat Diagn 2004;24:1049-1059.

$>10$ Kiserud T, Eik-Nes SH, Blaas HG, Hellevik LR: Foramen ovale: an ultrasonographic study of its relation to the inferior vena cava, ductus venosus and hepatic veins. Ultrasound Obstet Gynecol 1992;2:389-396. LR: Ultrasonographic velocimetry of the fetal ductus venosus. Lancet 1991;338:14121414.

12 Maiz N, Kagan KO, Milovanovic Z, Celik E, Nicolaides KH: Learning curve for Doppler assessment of ductus venosus flow at $11+0$ to $13+6$ weeks' gestation. Ultrasound Obstet Gynecol 2008;31:503-506.

$\checkmark 13$ Borrell A: Promises and pitfalls of first-trimester sonographic markers in the detection of fetal aneuploidy. Prenat Diagn 2009;29: $62-68$.

$\checkmark 14$ Hecher K, Campbell S, Snijders R, Nicolaides $\mathrm{K}$ : Reference ranges for fetal venous and atrioventricular blood flow parameters. Ultrasound Obstet Gynecol 1994;4:381-390.

15 Matias A, Gomes C, Flack N, Montenegro N, Nicolaides KH: Screening for chromosomal abnormalities at 10-14 weeks: the role of ductus venosus blood flow. Ultrasound $\mathrm{Ob}-$ stet Gynecol 1998;12:380-384.

16 Kiserud T: Hemodynamics of the ductus venosus. Eur J Obstet Gynecol Reprod Biol 1999;84:139-147.

17 Maiz N, Valencia C, Kagan KO, Wright D, Nicolaides KH: Ductus venosus Doppler in screening for trisomies 21, 18 and 13 and turner syndrome at 11-13 weeks of gestation. Ultrasound Obstet Gynecol 2009;33:512517.

18 Davies P, Dewar J, Tynan M, Ward R: Postnatal developmental changes in the lengthtension relationship of cat papillary muscles. J Physiol 1975;253:95-102.

19 Kaufman TM, Horton JW, White DJ, Mahony L: Age-related changes in myocardial relaxation and sarcoplasmic reticulum function. Am J Physiol 1990;259:H309-H316.
20 Van Splunder P, Stijnen T, Wladimiroff JW: Fetal atrioventricular, venous, and arterial flow velocity waveforms in the small for gestational age fetus. Pediatr Res 1997;42:765775 .

21 Matias A, Huggon I, Areias JC, Montenegro $\mathrm{N}$, Nicolaides KH: Cardiac defects in chromosomally normal fetuses with abnormal ductus venosus blood flow at 10-14 weeks. Ultrasound Obstet Gynecol 1999;14:307310.

22 Montenegro N, Matias A, Areias JC, Castedo $\mathrm{S}$, Barros H: Increased fetal nuchal translucency: possible involvement of early cardiac failure. Ultrasound Obstet Gynecol 1997;10: 265-268.

-23 Antolin E, Comas C, Torrents M, Munoz A, Figueras F, Echevarria M, Cararach M, Carrera JM: The role of ductus venosus blood flow assessment in screening for chromosomal abnormalities at 10-16 weeks of gestation. Ultrasound Obstet Gynecol 2001; 17: 295-300.

24 Murta CG, Moron AF, Avila MA, Weiner CP: Application of ductus venosus Doppler velocimetry for the detection of fetal aneuploidy in the first trimester of pregnancy. Fetal Diagn Ther 2002;17:308-314.

25 Zoppi MA, Putzolu M, Ibba RM, Floris M, Monni G: First-trimester ductus venosus velocimetry in relation to nuchal translucency thickness and fetal karyotype. Fetal Diagn Ther 2002;17:52-57.

26 Borrell A, Martinez JM, Seres A, Borobio V, Cararach V, Fortuny A: Ductus venosus assessment at the time of nuchal translucency measurement in the detection of fetal aneuploidy. Prenat Diagn 2003;23:921-926.

27 Toyama JM, Brizot ML, Liao AW, Lopes LM, Nomura RM, Saldanha FA, Zugaib M: Ductus venosus blood flow assessment at 11 to 14 weeks of gestation and fetal outcome. Ultrasound Obstet Gynecol 2004;23:341-345. 
28 Prefumo F, Sethna F, Sairam S, Bhide A, Thilaganathan B: First-trimester ductus venosus, nasal bones, and down syndrome in a high-risk population. Obstet Gynecol 2005; 105:1348-1354.

29 Bilardo CM, Muller MA, Zikulnig L, Schipper M, Hecher K: Ductus venosus studies in fetuses at high risk for chromosomal or heart abnormalities: relationship with nuchal translucency measurement and fetal outcome. Ultrasound Obstet Gynecol 2001; 17:288-294.

30 Borrell A, Borobio V, Bestwick JP, Wald NJ: Ductus venosus pulsatility index as an antenatal screening marker for down's syndrome: use with the combined and integrated tests. J Med Screen 2009;16:112-118.

- 31 Borrell A, Gonce A, Martinez JM, Borobio V, Fortuny A, Coll O, Cuckle H: First-trimester screening for down syndrome with ductus venosus Doppler studies in addition to nuchal translucency and serum markers. Prenat Diagn 2005;25:901-905.

-32 Maiz N, Plasencia W, Dagklis T, Faros E, Nicolaides K: Ductus venosus Doppler in fetuses with cardiac defects and increased nuchal translucency thickness. Ultrasound Obstet Gynecol 2008;31:256-260.
33 Haak MC, Twisk JW, Bartelings MM, Gittenberger-de Groot AC, van Vugt JM: Ductus venosus flow velocities in relation to the cardiac defects in first-trimester fetuses with enlarged nuchal translucency. Am J Obstet Gynecol 2003;188:727-733.

34 Favre R, Cherif Y, Kohler M, Kohler A, Hunsinger MC, Bouffet N, Tanghe M, Cancellier M, Nisand I: The role of fetal nuchal translucency and ductus venosus Doppler at 11-14 weeks of gestation in the detection of major congenital heart defects. Ultrasound Obstet Gynecol 2003;21:239-243.

35 Martinez JM, Comas M, Borrell A, Bennasar M, Gomez O, Puerto B, Gratacos E: Abnormal first-trimester ductus venosus blood flow: a marker of cardiac defects in fetuses with normal karyotype and nuchal translucency. Ultrasound Obstet Gynecol 2010;35: 267-272.

36 Hung JH, Fu CY, Lu JH, Hung CY: Ductus venosus blood flow resistance and congenital heart defects in the second trimester. J Clin Ultrasound 2008;36:72-78.

37 Gembruch U, Meise C, Germer U, Berg C, Geipel A: Venous Doppler ultrasound in 146 fetuses with congenital heart disease. Ultrasound Obstet Gynecol 2003;22:345-350.
8 Matias A, Montenegro N, Areias JC: Anticipating twin-twin transfusion syndrome in monochorionic twin pregnancy. Is there a role for nuchal translucency and ductus venosus blood flow evaluation at 11-14 weeks? Twin Res 2000;3:65-70.

39 Matias A, Montenegro N, Loureiro T, Cunha M, Duarte S, Freitas D, Severo M: Screening for twin-twin transfusion syndrome at 11-14 weeks of pregnancy: the key role of ductus venosus blood flow assessment. Ultrasound Obstet Gynecol 2010;35:142-148.

40 Sebire NJ, Talbert D, Fisk NM: Twin-to-twin transfusion syndrome results from dynamic asymmetrical reduction in placental anastomoses: a hypothesis. Placenta 2001;22:383391.

41 Sebire NJ, D’Ercole C, Hughes K, Carvalho $\mathrm{M}$, Nicolaides KH: Increased nuchal translucency thickness at 10-14 weeks of gestation as a predictor of severe twin-to-twin transfusion syndrome. Ultrasound Obstet Gynecol 1997;10:86-89.

-42 Kagan KO, Gazzoni A, Sepulveda-Gonzalez G, Sotiriadis A, Nicolaides KH: Discordance in nuchal translucency thickness in the prediction of severe twin-to-twin transfusion syndrome. Ultrasound Obstet Gynecol 2007; 29:527-532. 